\title{
Contamination of Streptococcus suis in pork and edible pig organs in central Thailand
}

\author{
Nuchjaree Boonyong, Sarawan Kaewmongkol, Duangdaow Khunbutsri, Khomsan Satchasataporn and Nattakan Meekhanon
}

Department of Veterinary Technology, Faculty of Veterinary Technology, Kasetsart University, Bangkok 10900, Thailand. Corresponding author: Nattakan Meekhanon, e-mail: Inattakan@yahoo.com

Co-authors: NB: nuchjaree513@hotmail.com, SK: cvtswt@ku.ac.th, DK: cvtddk@ku.ac.th, KS: cvtkss@ku.ac.th Received: 22-10-2018, Accepted: 17-12-2018, Published online: 29-01-2019

doi: 10.14202/vetworld.2019.165-169 How to cite this article: Boonyong $N$, Kaewmongkol S, Khunbutsri $D$, Satchasataporn K, Meekhanon N (2019) Contamination of Streptococcus suis in pork and edible pig organs in central Thailand, Veterinary World, 12(1): 165-169.

\begin{abstract}
Background and Aim: Streptococcus suis is an important zoonotic pathogen that can cause serious diseases in both swine and humans worldwide, especially in Asian countries. Since the majority of human cases reported in Thailand were infected by the consumption of a raw pork dish, the microbial food safety hazard associated with raw meat has been a matter of concern. Therefore, this study aimed to investigate the contamination by S. suis in pork and edible pig organs sold in central Thailand.

Materials and Methods: In total, 88 raw pork and pig organ samples were purchased from markets, butcher shops, and supermarkets in central Thailand. The samples were examined using the loop-mediated isothermal amplification (LAMP) technique. LAMP reactions used for the detection of the DNA of $S$. suis $\left(\mathrm{LAMP}_{\mathrm{SS}}\right)$ and $S$. suis serotype 2 or 1/2 $\left(\mathrm{LAMP}_{\mathrm{SS} 2}\right)$ were carried out according to previous studies.

Results: The percentage of LAMP ${ }_{\mathrm{ss}}$-positive samples was as high as $85.23 \%(75 / 88)$ while the percentage of LAMP $\mathrm{SS}^{-}$ positive samples was $17.05 \%(15 / 88)$. The percentages of $\mathrm{LAMP}_{\mathrm{Ss}}{ }^{-}$and $\mathrm{LAMP}_{\mathrm{SS} 2}$-positive samples were relatively high in both pig organs (lung and heart) and meat (sliced pork and minced pork) compared with the previous report. Except one supermarket, $\mathrm{LAMP}_{\mathrm{ss}}$-positive samples were found in all sources investigated in this study. The pork and pig organs obtained from the markets and the butcher shops additionally gave positive results for LAMP $\mathrm{SS}_{\mathrm{S} 2}$.

Conclusion: Using LAMP techniques, high rate contamination of S. suis was found in raw pork and edible pig organs sold at different sources in central Thailand. The cross-contamination could have occurred through slaughtering, meat cutting, and meat handling processes. Therefore, consumers and people involved in the pig production industry should be aware of the potential hazards of S. suis infection; food safety education is crucial to prevent further infection.
\end{abstract}

Keywords: contamination, loop-mediated isothermal amplification, pork, Streptococcus suis, Thailand.

\section{Introduction}

Streptococcus suis is a well-recognized zoonotic pathogen worldwide. S. suis infection can cause serious diseases in swine as well as severe consequences in humans. The most striking clinical feature found in infected patients is meningitis, and after recovery, the patients frequently suffer from permanent loss of hearing [1]. Other clinical manifestations including arthritis, endocarditis, pneumonia, septicemia, and septic shock have been reported in human infections [1]. Since the first human $S$. suis infection was reported in Denmark in $1968,>1600$ human cases have occurred in many countries, particularly in Vietnam, Thailand, and China [2]. Although direct contact through a wound is the main transmission route of human infection, the majority of human cases reported in Vietnam and Thailand were infected by the consumption of raw pork and offal $[3,4]$.

Copyright: Boonyong, et al. Open Access. This article is distributed under the terms of the Creative Commons Attribution 4.0 International License (http://creativecommons.org/licenses/ by/4.0/), which permits unrestricted use, distribution, and reproduction in any medium, provided you give appropriate credit to the original author(s) and the source, provide a link to the Creative Commons license, and indicate if changes were made. The Creative Commons Public Domain Dedication waiver (http:// creativecommons.org/publicdomain/zero/1.0/) applies to the data made available in this article, unless otherwise stated.
Based on the various capsular polysaccharide (CPS) antigens, S. suis strains have been classified into different serotypes [2]. Of the serotypes described so far, $S$. suis serotype 2 is the most prevalent and pathogenic for both pigs and humans $[5,6]$. In addition, other serotypes including serotypes $1,4,5,9,14$, $16,21,24$, and 31 have been occasionally reported in human cases [2,7-12]. Since S. suis serotype 2 and the other potential hazardous strains could be found even in the slaughtered pigs $[13,14]$, contamination by $S$. suis in pork and pig organs should be taken into account as it could lead to a high risk of human infection. Loop-mediated isothermal amplification (LAMP) specific to $S$. suis, which was previously described elsewhere [15], was used to detect S. suis in this study. Since LAMP is simple, fast, and sensitive, this technique can be used as a surveillance tool for the detection of $S$. suis contamination. Accordingly, LAMP techniques targeting the gene-encoding recombination/repair protein (recN) and the CPS synthesis gene specific for serotype 2 and $1 / 2$ (cps $2 J)$ can be used for the detection of $S$. suis and $S$. suis serotype 2 or $1 / 2$, respectively $[15,16]$.

Central Thailand is not only the center of the country's economy, transportation, and tourism but is 
also a region where the pig density is high. Therefore, in this study, we aimed to investigate $S$. suis contamination in pork and edible pig organs sold in retail markets, butcher shops, and supermarkets in central Thailand. The results from this study will provide important insights into the risk management of this emerging zoonotic pathogen in food.

\section{Materials and Methods}

\section{Ethical approval}

As live animals were not used, ethical approval for animal research was not required in this study. Pork and pig organ samples were purchased from local markets, butcher shops, and supermarkets in central Thailand.

\section{Sample collection and preparation}

In total, 88 samples, consisting of 50 raw pork samples (27 sliced pork and 23 minced pork) and 38 pig organ samples (16 livers, 13 lungs, and 9 hearts), were purchased from 20 sources (eight markets, eight butcher shops, and four supermarkets) in central Thailand between July 2016 and December 2017. The samples were immediately transported to the Faculty of Veterinary Technology, Kasetsart University, Bangkok, Thailand, and were prepared for S. suis detection following a previous study [15] with slight modifications. Briefly, each sample was aseptically cut into small pieces, and $100 \mathrm{~g}$ of each sample was subsequently homogenized with the appropriate amount $(20-100 \mathrm{ml})$ of $0.9 \%$ saline solution in a sterile stomacher bag for $2 \mathrm{~min}$ at $230 \mathrm{rpm}$ using a Stomacher $^{\circledR} 400$ circulator (Scientific Promotion Co., Ltd., UK). Then, $100 \mu$ l of the solution obtained from homogenization was added to $5 \mathrm{ml}$ of Todd-Hewitt broth supplemented with Streptococcus Selective Supplement (Oxoid, UK). After incubation at $37^{\circ} \mathrm{C}$ for $18-24 \mathrm{~h}, 1 \mathrm{ml}$ of each bacterial culture was used for DNA extraction.

\section{Molecular techniques}

\section{DNA extraction}

The genomic DNA was extracted using InstaGene Matrix $^{\circledR}$ (Bio-Rad Laboratories, Inc., United States) according to the manufacturer's recommendations. All genomic DNA samples were stored at $-20^{\circ} \mathrm{C}$ until used.

\section{LAMP}

LAMP reactions used for the detection of DNA of $S$. suis $\left(\mathrm{LAMP}_{\mathrm{SS}}\right)$ and $S$. suis serotype 2 or $1 / 2\left(\mathrm{LAMP}_{\mathrm{SS} 2}\right)$ were carried out according to Arai et al. [15] and Zhang et al. [16], respectively. The primer sets are shown in Table-1 $[15,16]$ and consisted of two inner primers (forward inner primer [FIP] and backward inner primer [BIP]), two outer primers (F3 and B3), and an LB loop primer. The primers in each reaction mixture contained $0.2 \mu \mathrm{M}$ each of $\mathrm{F} 3$ and B3, $1.6 \mu \mathrm{M}$ each of FIP and BIP, and $0.8 \mu \mathrm{M}$ of LB loop primer. LAMP reactions were performed using a Loopamp DNA amplification kit (Eiken Chemical Co., Ltd., Japan) using the GeneAmp ${ }^{\circledR}$ PCR system 9700 (Applied Biosystem, Singapore). LAMP SS reaction was carried out at $60^{\circ} \mathrm{C}$ for $60 \mathrm{~min}$ followed by inactivation at $80^{\circ} \mathrm{C}$ for $5 \mathrm{~min}$. The samples which gave a positive result for $\mathrm{LAMP}_{\mathrm{SS}}$ were further examined using $\mathrm{LAMP}_{\mathrm{SS} 2}$. $\mathrm{LAMP}_{\mathrm{SS} 2}$ was performed at $63^{\circ} \mathrm{C}$ for $60 \mathrm{~min}$ and was then inactivated at $85^{\circ} \mathrm{C}$ for $2 \mathrm{~min}$. In all reactions, S. suis strain P1/7 [17] and distilled water were used as positive and negative controls, respectively.

\section{LAMP product detection}

Gel electrophoresis was used to analyze the products of both LAMP $_{\mathrm{SS}}$ and LAMP ${ }_{\mathrm{SS} 2}$ by HE-Plus Electrophoresis (Hoefer, U.S.A). An UltraSlim ${ }^{\circledR}$ LED illuminator (Maestrogen, Taiwan) was used to observe the bands of products, and the samples were considered to be positive if they showed a ladder-like band pattern (Figure-1).

\section{Results}

All sample types investigated in this study gave positive results with both $\mathrm{LAMP}_{\mathrm{SS}}$ and $\mathrm{LAMP}_{\mathrm{SS} 2}$ analyses, as shown in Table-2. The percentage of $\mathrm{LAMP}_{\mathrm{SS}}{ }^{-}$ positive samples was as high as $85.23 \%(75 / 88)$ while the percentage of $\mathrm{LAMP}_{\mathrm{SS} 2}$-positive sample was $17.05 \%(15 / 88)$. The highest percentage of $\mathrm{LAMP}_{\mathrm{SS}}{ }^{-}$ positive samples was in the lung $(92.31 \%)$, followed by the heart $(88.89 \%)$ and sliced pork $(88.89 \%)$, while the lowest percentage of LAMP ${ }_{\mathrm{SS}}$-positive samples was in the liver. Similar to LAMP ${ }_{\mathrm{SS}}$, the results from LAMP ${ }_{\mathrm{SS} 2}$ analysis showed that the percentage

Table-1: Primer sequences of LAMP ${ }_{S S}$ and $L_{A M P}$ SS2 used in this study.

\begin{tabular}{|c|c|c|c|}
\hline Assay & Primer & Primer sequence $\left(5^{\prime}-3^{\prime}\right)$ & References \\
\hline \multirow{5}{*}{ LAMP $_{S S}$} & F3 & TGTCGATGATGTTITGGACTA & [15] \\
\hline & B3 & GCTITCTCCATATACAAGTCTTG & \\
\hline & FIP & AAGCTGAACTTCCAAATCATCTCCCAGCGAAGAATACAATCTATTGAC & \\
\hline & BIP & TAGAGAAAGAATTGGTTGAACGAGCGCGGATAATATCTTCTAAAACAAC & \\
\hline & LB & GGTCAGCTCAGCCAATCACGC & \\
\hline \multirow[t]{5}{*}{ LAMP $_{\mathrm{SS} 2}$} & F3 & GTGTITCAAACGAAGGAAT & [16] \\
\hline & B3 & GCACCTCTTITATCTCTTCCAA & \\
\hline & FIP & GTTGCCGTCAACAATATCATCAGAACGGTATCAAAAATAGCACAGC & \\
\hline & BIP & AGAGAATGATAGTGATTTGTCGGG TTTGCAGCTCAGATTCTTG & \\
\hline & LB & AGGGTTACTTGCTACTTITGATGG & \\
\hline
\end{tabular}

LAMP=Loop-mediated isothermal amplification, BIP=Backward inner primer, FIP=Forward inner primer 
Table-2: Meat samples used in this study and LAMP results.

\begin{tabular}{|c|c|c|c|}
\hline Sample type & $\begin{array}{l}\text { Number of } \\
\text { samples }\end{array}$ & $\begin{array}{c}\text { Number of LAMP } \\
\text { samples }(\%)\end{array}$ & $\begin{array}{c}\text { Number of LAMP } \text { ss2 } \text {-positive } \\
\text { samples }(\%)\end{array}$ \\
\hline Sliced pork & 27 & $24(88.89)$ & $5(18.52)$ \\
\hline Minced pork & 23 & $20(86.96)$ & $4(17.39)$ \\
\hline Liver & 16 & $11(68.75)$ & $0(0)$ \\
\hline Lung & 13 & $12(92.31)$ & $4(30.77)$ \\
\hline Heart & 9 & $8(88.89)$ & $2(22.22)$ \\
\hline Total & 88 & $75(85.23)$ & $15(17.05)$ \\
\hline
\end{tabular}

LAMP $=$ Loop-mediated isothermal amplification

Table-3: Sources of samples used in this study and LAMP results.

\begin{tabular}{lccc}
\hline Sample source & $\begin{array}{c}\text { Number of sample } \\
\text { source }\end{array}$ & $\begin{array}{c}\text { Number of sources containing } \\
\text { LAMP }_{\text {ss }} \text {-positive sample (\%) }\end{array}$ & $\begin{array}{c}\text { Number of sources containing } \\
\text { LAMP }_{\text {ss2 }} \text {-positive sample (\%) }\end{array}$ \\
\hline Market & 8 & $8(100)$ & $6(75)$ \\
Butcher shop & 8 & $8(100)$ & $4(50)$ \\
Supermarket & 4 & $3(75)$ & $0(0)$ \\
Total & 20 & $19(95)$ & $10(50)$ \\
\hline
\end{tabular}

LAMP $=$ Loop-mediated isothermal amplification

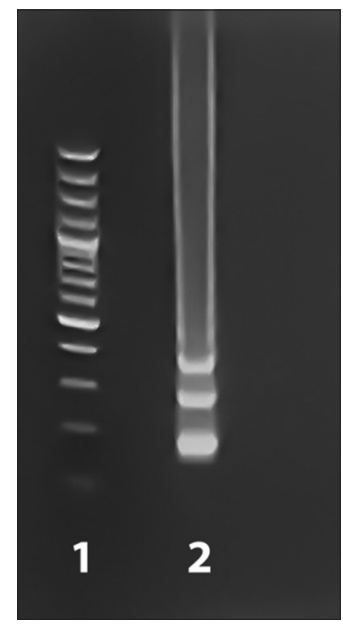

Figure-1: Agarose gel electrophoresis under LED illuminator used to observe the band of loop-mediated isothermal amplification (LAMP) products, where a positive result of LAMP shows a ladder-like band pattern. Lane 1, 100 bp Plus DNA Ladder; Lane 2, LAMP-positive sample.

of LAMP ${ }_{\mathrm{SS} 2}$-positive sample was highest in the lung $(30.77 \%)$ followed by the heart $(22.22 \%)$ and sliced pork $(18.52 \%)$ (Table-2).

The results of LAMP analyses classified by the type of sample source are shown in Table-3. Except for one supermarket, $\mathrm{LAMP}_{\mathrm{ss}}$-positive samples were found at all sources investigated in this study. The samples collected from 10 of the 20 sources $(50 \%)$ additionally had positive results for $\mathrm{LAMP}_{\mathrm{SS} 2}$. All samples obtained from supermarkets were LAMP ${ }_{\mathrm{SS} 2}$ negative, while the samples collected from 6 markets $(75 \%)$ and 4 butcher shops $(50 \%)$ were $\mathrm{LAMP}_{\mathrm{SS} 2}$ positive.

\section{Discussion}

Among $S$. suis infections reported in humans worldwide, $>90 \%$ of cases have occurred in Asian countries, particularly in Vietnam and Thailand [18]. Since the major cause of $S$. suis human infection in this area is the consumption of a raw pork dish, the microbial food safety hazard associated with raw meat has been raised as a matter of great concern. Therefore, in this study, we investigated the contamination by $S$. suis and $S$. suis serotype 2 or $1 / 2$ in raw pork and edible pig organs sold at different sources in central Thailand using LAMP techniques. Our results showed high contamination rates by $S$. suis in pork and pig organs. In addition, contamination by S. suis serotype 2 or $1 / 2$ was found in the samples purchased from markets and butcher shops. S. suis and S. suis serotype 2 or $1 / 2$ contamination rates in this study were much higher than those reported in a previous study [15], in which the contamination rates of S. suis and $S$. suis serotype 2 or $1 / 2$ in raw pork meat samples in Japan were $26.4 \%$ and $4.87 \%$, respectively.

In addition, they found that the rate of contamination in pig organs was higher than in pork. Likewise, contamination by $S$. suis was reported in the tongue, tonsil, bone, and tail, but not in pork meat collected from wet markets in Hong Kong [19]. On the contrary, the contamination rates of $S$. suis and $S$. suis serotype 2 or $1 / 2$, in our study, were relatively high in both the pig organs (lung and heart) and meat (sliced pork and minced pork) samples. Although S. suis can be found in the tonsil, nasal cavities, and reproductive and digestive tracts of healthy pigs, this bacterium should not be found in sterile sites such as muscle, blood, heart, lung, and liver of a healthy pig [20]. Our findings indicated the possibility of the cross-contamination between visceral organs and pork meat which could occur through slaughtering, meat cutting, meat handling, and further processing [21].

Although many attempts were made, we failed to isolate $S$. suis from the LAMP-positive samples. Since one of the main advantages of LAMP over traditional culture techniques is its sensitivity, it could be suggested that the number of vegetative $S$. suis cells may be too low to compete with the other non-fastidious bacteria contaminating the same sample. Thus, the 
presence of viable $S$. suis could not be detected using bacterial cultivation. Similarly, Cheung et al. [22] revealed that it was difficult to isolate $S$. suis from raw pork meat samples due to the low levels of live $S$. suis cells coexisting with many other microorganisms. However, the retrieval of $S$. suis isolate is required for other important information including virulence and antibiotic resistance traits. Accordingly, it is necessary to further investigate the characteristics of $S$. suis isolates contaminated in raw pork for a better approach to the food safety risk analysis.

Contamination by S. suis in raw pork meat was found in all markets and butcher shops examined in this study. Moreover, the samples contaminated with $S$. suis serotype 2 or $1 / 2$ were obtained from 6 of the 8 markets $(75 \%)$ and 4 of the 8 butcher shops $(50 \%)$, but no contaminated samples were obtained from the supermarkets. These results emphasized the problem of sanitation and hygienic practices in local retail shops and markets in Thailand. We noticed that the meat handlers in the market stalls worked without gloves and they usually used the same utensils, such as a chopping board and knife, for all meat types. Due to the high contamination rate, the consumers, as well as people who were in close contact with raw pork and pig organs, have a high risk of $S$. suis infection. The achievements from a food safety campaign on the control of $S$. suis infection in Northern Thailand have been described [23]. Therefore, food safety education and public health intervention are crucial to effectively prevent and control the infection of this zoonotic pathogen throughout high-risk areas.

\section{Conclusion}

Using LAMP techniques, high rate contamination of $S$. suis was found in raw pork and edible pig organs sold at different sources in central Thailand. Contamination by $S$. suis serotype 2 or $1 / 2$ was additionally found in samples purchased from markets and butcher shops. It is suggested that the cross-contamination between visceral organs and pork meat possibly occurred during slaughtering, meat cutting, meat handling, and further processing. Therefore, food safety education is necessary to prevent $S$. suis infection.

\section{Authors' Contributions}

NB collected samples, performed experiments, and wrote the manuscript. SK, DK, and KS provided technical help during the experiments. NM conceived the work, designed the experiments, collected samples, and revised the manuscript critically for important intellectual content. All authors have read and approved the final manuscript.

\section{Acknowledgments}

This study was financially supported by the Graduate School, Kasetsart University, Bangkok, Thailand, the Kasetsart University Research and Development Institute (Grant no. 37.59) and the
Capacity Building of Kasetsart University Students on Internationalization program. We are grateful to Prof. Tsutomu Sekizaki and Assoc. Prof. Daisuke Takamatsu for their scientific help.

\section{Competing Interests}

The authors declare that they have no competing interests.

\section{Publisher's Note}

Veterinary World remains neutral with regard to jurisdictional claims in published institutional affiliation.

\section{References}

1. Lun, Z.R., Wang, Q.P., Chen, X.G., Li, A.X. and Zhu, X.Q. (2007) Streptococcus suis: An emerging zoonotic pathogen. Lancet Infect. Dis., 7(3): 201-209.

2. Goyette-Desjardins, G., Auger, J.P., Xu, J., Segura, M. and Gottschalk, M. (2014) Streptococcus suis, an important pig pathogen and emerging zoonotic agent-an update on the worldwide distribution based on serotyping and sequence typing. Emerg. Microbes. Infect., 3(6): e45.

3. Huong, V.T.L., Hoa, N.T., Horby, P., Bryant, J.E., Kinh, N.V., Toan, T.K. and Wertheim, H.F.L. (2014) Raw pig blood consumption and potential risk for Streptococcus suis infection, Vietnam. Emerg. Infect. Dis., 20(11): 1895-1898.

4. Kerdsin, A., Dejsirilert, S., Sawanpanyalert, P., Boonnark, A., Noithachang, W., Sriyakum, D., Simkum, S., Chokngam, S., Gottschalk, M., Akeda, Y. and Oishi, K. (2011) Sepsis and spontaneous bacterial peritonitis in Thailand. Lancet, 378(9794): 960.

5. Gottschalk, M. and Segura, M. (2000) The pathogenesis of meningitis caused by Streptococcus suis: The unresolved questions. Vet. Microbiol., 76(3): 259-272.

6. Madsen, L.W., Svensmark, B., Elvestad, K., Aalbaek, B. and Jensen, H.E. (2002) Streptococcus suis serotype 2 infection in pigs: New diagnostic and pathogenetic aspects. J. Comp. Pathol., 126(1): 57-65.

7. Kerdsin, A., Dejsirilert, S., Puangpatra, P., Sripakdee, S., Chumla, K., Boonkerd, N., Polwichai, P., Tanimura, S., Takeuchi, D., Nakayama, T., Nakamura, S., Akeda, Y., Gottschalk, M., Sawanpanyalert, P. and Oishi, K. (2011) Genotypic profile of Streptococcus suis serotype 2 and clinical features of infection in humans, Thailand. Emerg Infect. Dis., 17(5): 835-842.

8. Kerdsin, A., Hatrongjit, R., Gottschalk, M., Takeuchi, D., Hamada, S., Akeda, Y. and Oishi, K. (2017) Emergence of Streptococcus suis serotype 9 infection in humans. $J$. Microbiol. Immunol., 50(4): 545-546.

9. Nghia, H.D.T., Ngo, T.H., Le, D.L., Campbell, J., To, S.D., Chau, N.V.V., Mai, N.T.H., Tran, T.H., Spratt, B., Farrar, J. and Schultsz, C. (2008) Human case of Streptococcus suis serotype 16 infection. Emerg. Infect. Dis., 14(1): 155-157.

10. Takeuchi, D., Kerdsin, A., Pienpringam, A., Loetthong, P., Samerchea, S., Luangsuk, P., Khamisara, K., Wongwan, N., Areeratana, P., Chiranairadul, P., Lertchayanti, S., Petcharat, S., Yowang, A., Chaiwongsaen, P., Nakayama, T., Akeda, Y., Hamada, S., Sawanpanyalert, P., Dejsirilert, S. and Oishi, K. (2012) Population-based study of Streptococcus suis infection in humans in Phayao province in Northern Thailand. PLoS One, 7(2): e31265.

11. Taniyama, D., Sakurai, M., Sakai, T., Kikuchi, T. and Takahashi, T. (2016) Human case of bacteremia due to Streptococcus suis serotype 5 in Japan: The first report and literature review. ID Cases, 6(5): 36-38.

12. Wertheim, H.F.L., Nghia, H.D.T., Taylor, W. and Schultsz, C. (2009) Streptococcus suis: An emerging human 
pathogen. Clin. Infect. Dis., 48(5): 617-625.

13. Meekhanon, N., Kaewmongkol, S., Phimpraphai, W., Okura, M., Osaki, M., Sekizaki, T. and Takamatsu, D. (2017) Potentially hazardous Streptococcus suis strains latent in asymptomatic pigs in a major swine production area of Thailand. J. Med. Microbiol., 66(5): 662-669.

14. Wang, K., Zhang, W., Li, X., Lu, C., Chen, J., Fan, W. and Huang, B. (2013) Characterization of Streptococcus suis isolates from slaughter swine. Curr. Microbiol., 66(4): 344-349.

15. Arai, S., Tohya, M., Yamada, R., Osawa, R., Nomoto, R., Kawamura, Y. and Sekizaki, T. (2015) Development of loop-mediated isothermal amplification to detect Streptococcus suis and its application to retail pork meat in Japan. Int. J. Food Microbiol., 208: 35-42.

16. Zhang, J., Zhu, J., Ren, H., Zhu, S., Zhao, P., Zhang, F., Lv, H., Hu, D., Hao, L., Geng, M., Gong, X., Pan, X., Wang, C. and Qi, Z. (2013) Rapid visual detection of highly pathogenic Streptococcus suis serotype 2 isolates by use of loop-mediated isothermal amplification. J. Clin. Microbiol., 51(10): 3250-3256.

17. Slater, J.D., Allen, A.G., May, J.P., Bolitho, S., Lindsay, H. and Maskell, D.J. (2003) Mutagenesis of Streptococcus equi and Streptococcus suis by transposon Tn917. Vet. Microbiol., 93(3): 197-206.

18. Dutkiewicz, J., Sroka, J., Zajac, V., Wasinski, B., Cisak, E., Sawczyn, A., Kloc, A. and Wojcik-Fatla, A. (2017) Streptococcus suis: A re-emerging pathogen associated with occupational exposure to pigs or pork products. Part I - Epidemiology. Ann. Agric. Environ. Med., 24(4): 683-695.

19. Ip, M., Fung, K.S., Chi, F., Cheuk, E.S., Chau, S.S., Wong, B.W., Lui, S., Hui, M., Lai, R.W. and Chan, P.K. (2007) Streptococcus suis in Hong Kong. Diagn. Microbiol. Infect. Dis., 57(1): 15-20.

20. Feng, Y., Zhang, H., Wu, Z., Wang, S., Cao, M., Hu, D. and Wang, C. (2014) Streptococcus suis infection: An emerging/reemerging challenge of bacterial infectious diseases? Virulence, 5(4): 477-497.

21. Adesokan, H.K. and Raji, A.O.Q. (2014) Safe meat-handling knowledge, attitudes and practices of private and government meat processing plants' workers: Implications for future policy. J. Prev. Med. Hyg., 55(1): 10-16.

22. Cheung, P.Y., Lo, K.L., Cheung, T.T., Yeung, W.H., Leung, P.H. and Kam, K.M. (2008) Streptococcus suis in retail markets: How prevalent is it in raw pork? Int. J. Food Microbiol., 127(3): 316-320.

23. Takeuchi, D., Kerdsin, A., Akeda, Y., Chiranairadul, P., Loetthong, P., Tanburawong, N., Areeratana, P., Puangmali, P., Khamisara, K., Pinyo, W., Anukul, R., Samerchea, S., Lekhalula, P., Nakayama, T., Yamamoto, K., Hirose, M., Hamada, S., Dejsirilert, S. and Oishi, K. (2017) Impact of a food safety campaign on Streptococcus suis infection in humans in Thailand. Am. J. Trop. Med. Hyg., 96(6): 1370-1377. 